\title{
Delayed Tracheostomy in a Patient With Prolonged Invasive Mechanical Ventilation due to COVID-19
}

\author{
Ian C. Holmen ${ }^{1}$, Andrew Kent ${ }^{2}$, Stephanie Lakritz ${ }^{2}$, Claire Brickson ${ }^{3}$, Katarzyna Mastalerz ${ }^{4,5}$ \\ 1. Anesthesiology, University of Colorado, Denver, USA 2. Internal Medicine, University of Colorado, Denver, USA 3. \\ Internal Medicine, University of Colorado Anschutz Medical Campus, Denver, USA 4. Hospital Medicine, Eastern \\ Colorado Veterans Affairs Medical Center, Aurora, USA 5. Hospital Medicine, University of Colorado, Aurora, USA
}

Corresponding author: Ian C. Holmen, ianholmen@gmail.com

\begin{abstract}
Coronavirus disease 2019 (COVID-19) can cause acute respiratory distress syndrome (ARDS) that is associated with high mortality among patients requiring invasive mechanical ventilation. We present a case of a 56-year-old male with hypertension and obesity who presented with chest pain from COVID-19. The patient required endotracheal intubation due to worsening hypoxia and remained intubated for 33 days. Tracheostomy placement was delayed in part due to persistent COVID-19 positive testing until hospital day 37. The patient required a total of 52 days in the ICU prior to discharge to a rehabilitation facility. This case highlights the extensive resources needed for critically ill patients with COVID-19 and the long duration that patients may test positive for the virus after onset of symptoms. It also raises questions about the timing and safety of tracheostomy placement among those patients requiring mechanical ventilation from COVID19.
\end{abstract}

Categories: Internal Medicine, Otolaryngology, Infectious Disease

Keywords: endotracheal intubation, tracheostomy placement, acute respiratory distress syndrome

\section{Introduction}

Coronavirus disease 2019 (COVID-19) causes acute respiratory distress syndrome (ARDS) [1]. In a retrospective review from Wuhan, China, 26\% of patients hospitalized for COVID-19 required ICU admission due to ARDS [2]. Twelve percent of patients in the New York City area admitted for COVID-19 needed endotracheal intubation, and mortality for those requiring invasive mechanical ventilation reached as high as $88.1 \%$ [3]. While there have been significant data on the mortality of patients requiring mechanical ventilation no previous case reports have detailed the clinical timeline of respiratory recovery in those requiring tracheostomy placement.

Received 06/01/2020 Review began 06/09/2020 Review ended 06/11/2020 Published 06/15/2020

(c) Copyright 2020 Holmen et al. This is an open access article distributed under the terms of the Creative Commons Attribution License CC-BY 4.0 , which permits unrestricted use, distribution, and reproduction in any medium, provided the original author and source are credited.

\section{Case Presentation}

A 56-year-old male with obesity, hypertension, and scoliosis presented to the hospital for dull, atypical chest pain. He was febrile to 38.0 degrees Celsius and had a new oxygen requirement of two liters on nasal cannula for a blood oxygen saturation $\left(\mathrm{SpO}_{2}\right)$ of $96 \%$. His HEART score was four [4]. His initial D-dimer was $790 \mathrm{ng} / \mathrm{mL}$, and his initial troponin in the ED was $0.077 \mathrm{ng} / \mathrm{mL}$ (normal less than $0.015 \mathrm{ng} / \mathrm{mL}$ ), without evidence of dynamic changes on electrocardiogram (EKG). A respiratory viral panel was negative. CT angiography scan showed no signs of pulmonary embolism, and chest X-ray demonstrated normal lung findings without definitive acute infiltrates (Figure 1). The patient was admitted for hypoxia and acute coronary syndrome rule out. Repeat troponin level at six hours after admission decreased to $0.06 \mathrm{ng} / \mathrm{mL}$. Given the patient's new hypoxia and chest pain, a COVID-19 nasal swab was collected. 


\section{Cureus}

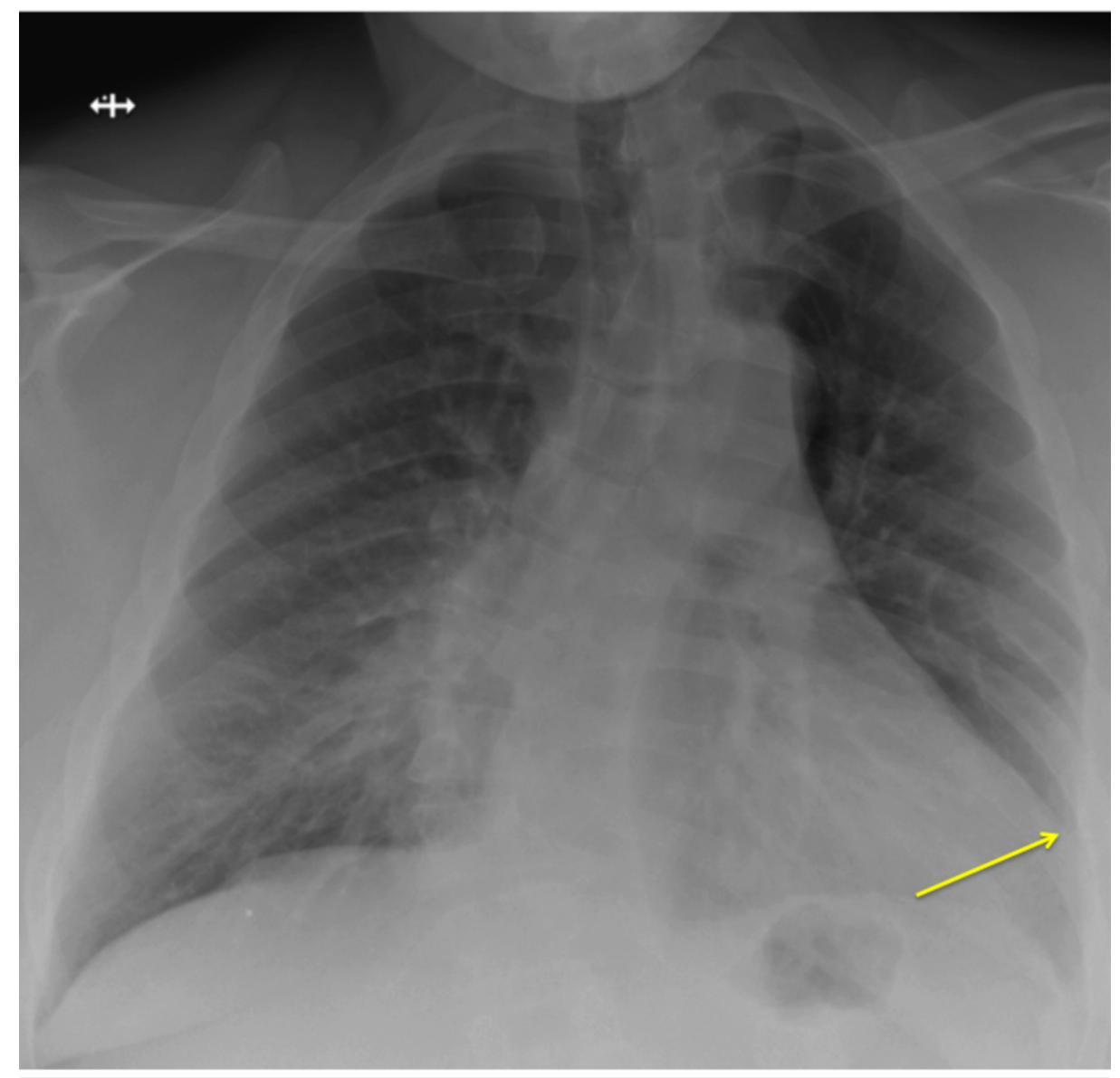

FIGURE 1: Chest X-ray on admission revealed normal lung findings and cardiomegaly. Yellow arrow indicating left lateral boarder of enlarged cardiac silhouette.

On hospital day three, bilateral crackles on exam were presumed to be pulmonary edema, and he was diuresed with IV furosemide. However, diuresis was discontinued due to a subsequent acute kidney injury. On hospital day four, COVID-19 polymerase chain reaction (PCR) resulted positive, and the patient was started on a 10-day course of hydroxychloroquine. On hospital day five, the patient had worsening tachypnea and $\mathrm{SpO} 2$ was $78 \%$ despite six liters oxygen via nasal cannula. The patient consented for invasive mechanical ventilation. Immediately following endotracheal intubation, arterial blood gas demonstrated a ratio of arterial oxygen partial pressure to fractional inspired oxygen (P/F ratio) of 77. Repeat chest X-ray showed bilateral diffuse infiltrates consistent with severe ARDS (Figure 2). Over the next two days, the patient was placed in the prone position for 18 hours a day and was intermittently paralyzed with cisatracurium. Positive end-expiratory pressure (PEEP) was initiated at $20 \mathrm{cmH}_{2} \mathrm{O}$ with $6 \mathrm{~mL} / \mathrm{kg}$ low tidal volume ventilation. Plateau pressures remained below $30 \mathrm{cmH}_{2} 0$ with at this level of PEEP. 


\section{Cureus}

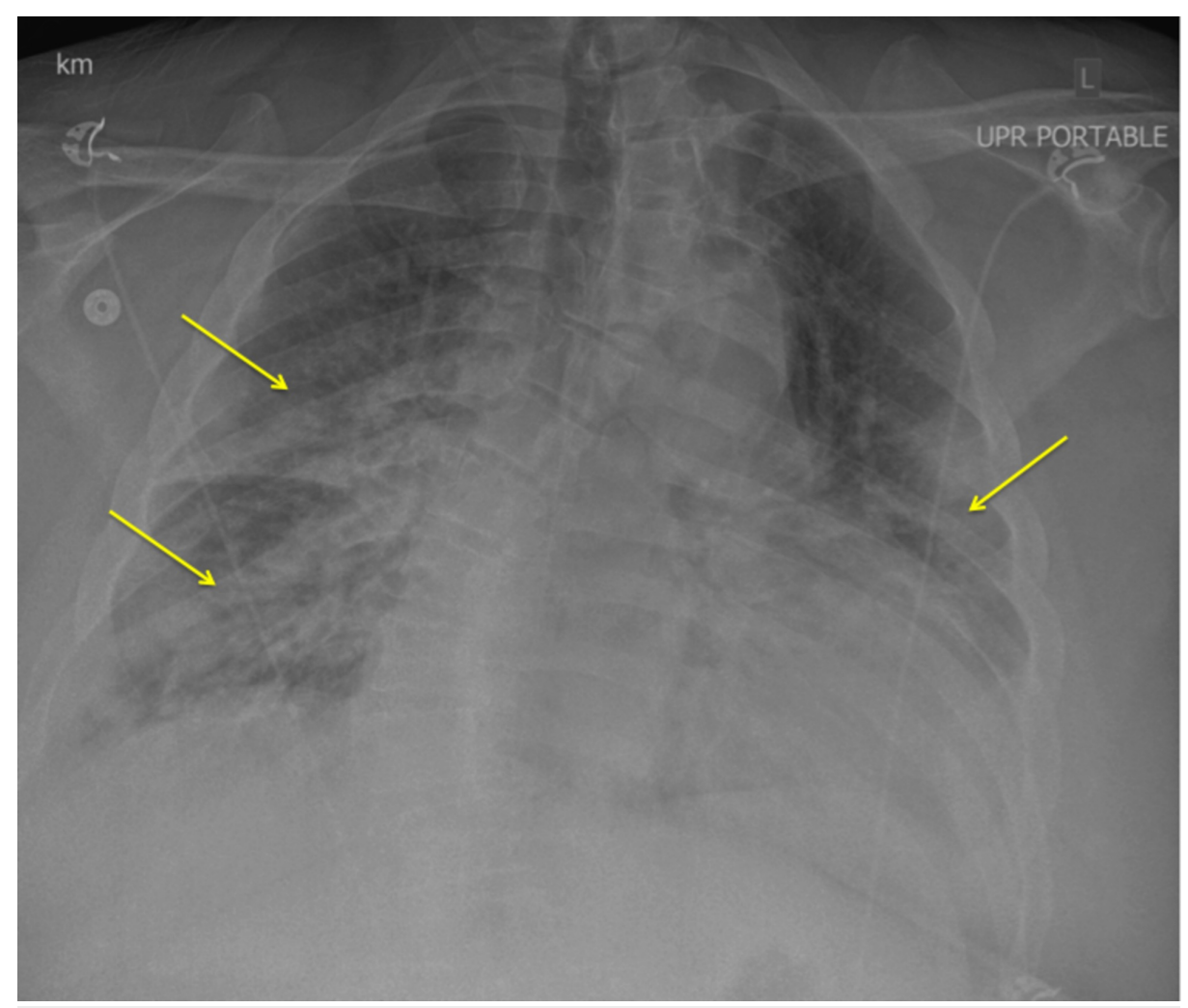

\section{FIGURE 2: Chest X-ray (day 5) revealed bilateral infiltrates. Yellow arrows demonstrate increased opacity bilaterally.}

The patient continued to require mechanical ventilation with an endotracheal tube for the next 27 days. After the two days of intermittent prone positioning, oxygen saturation improved gradually over 14 days. The P/F ratio stabilized at greater than 200 on a PEEP of 5-7 $\mathrm{cmH}_{2} \mathrm{O}$ with $\mathrm{FiO}_{2}$ at $40 \%$. Despite improvement in respiratory status, impaired mental status precluded extubation for several weeks. On hospital day 32, he was extubated to nonrebreather mask with $10 \mathrm{~L}$ oxygen supplementation.

Four days following extubation, on hospital day 36, he required re-intubation for hypercarbic respiratory failure. The patient had negative COVID-19 nasopharyngeal testing for the first time on hospital day 37, and consequently was scheduled for tracheostomy placement on hospital day 41 . After tracheostomy, the patient had continued need for PEEP of $5 \mathrm{~cm} \mathrm{H}_{2} \mathrm{O}$ and supplemental oxygen. The patient was completely weaned

from pressure support on hospital day 55, 52 of which were in the ICU. He was discharged to a rehabilitation center after hospital day 58.

\section{Discussion}

We present a case of COVID-19 requiring prolonged endotracheal intubation with mechanical ventilation for 33 days. The patient ultimately required tracheostomy placement prior to recovery and discharge. Literature to date has demonstrated high mortality among patients requiring invasive mechanical ventilation $[3,5]$. Little information has been published regarding the course of recovery and timing of tracheostomy in COVID-19 case reports.

Prior reports from Wuhan, China suggested the median ICU length of stay for patients with COVID-19 was 8 days [2]. Here we report a 58-day hospitalization requiring 52 days in the ICU due to continued need for mechanical ventilation. It is also noteworthy that the patient continued to test positive for COVID-19 until 37 days after admission. Prior research suggests that viral shedding after symptom onset gradually decreases toward undetectable levels around day 21 , which is significantly shorter than what we report [6]. While this case may demonstrate an outlier regarding time to negative COVID-19 testing in a patient with severe ARDS, some patients may still be infectious beyond the typical three-week period. It also demonstrates the level of intensive healthcare resources that may be needed to allow patients to recover.

To our knowledge, this is the longest course of endotracheal intubation and mechanical ventilation with survival that has been reported in the COVID-19 literature. Prior research in patients with pneumonia requiring mechanical ventilation suggests that tracheostomy placement within seven days of endotracheal intubation is associated with improved mortality, shorter ICU stays, and fewer days of mechanical 
ventilation compared tracheostomy placement between 14 and 21 days [7-8]. In this case, tracheostomy placement was delayed due to persistently positive COVID-19 PCR coupled with the possibility of successful extubation given the patient's improving respiratory status. In order to improve individual patient outcomes, and to better optimize ICU capacity during this pandemic, earlier tracheostomy placement could be considered. However, the benefits of early tracheostomy need to be balanced with the risk of aerosolgenerating procedures and healthcare worker risk of infection [9].

\section{Conclusions}

This case of COVID-19 infection illustrates prolonged endotracheal intubation, ICU stay, and viral shedding in a patient who ultimately recovered. The clinical trajectory may help inform decision making in similar COVID-19 infection cases in the future. Furthermore, this case raises important clinical questions regarding timing of tracheostomy placement. Decisions on timing may impact ICU capacity during the course of the COVID-19 pandemic given the prolonged hospital stays in critically ill patients.

\section{Additional Information}

\section{Disclosures}

Human subjects: Consent was obtained by all participants in this study. Conflicts of interest: In compliance with the ICMJE uniform disclosure form, all authors declare the following: Payment/services info: All authors have declared that no financial support was received from any organization for the submitted work. Financial relationships: All authors have declared that they have no financial relationships at present or within the previous three years with any organizations that might have an interest in the submitted work. Other relationships: All authors have declared that there are no other relationships or activities that could appear to have influenced the submitted work.

\section{References}

1. Gattinoni L, Chiumello D, Rossi S: COVID-19 pneumonia: ARDS or not? Crit Care. 2020, 16:154. 10.1186/s13054-020-02880-Z

2. Zhou F, Yu T, Du R, et al.: Clinical course and risk factors for mortality of adult inpatients with COVID-19 in Wuhan, China: a retrospective cohort study. Lancet. 2020, 28:1054-1062. 10.1016/S0140-6736(20)305663

3. Richardson S, Hirsch J, Narasimhan M, et al.: Presenting characteristics, comorbidities, and outcomes among 5700 patients hospitalized with COVID-19 in the New York City area. JAMA. 2020, 10.1001/jama.2020.6775

4. Brady W, de Souza K: The HEART score: a guide to its application in the emergency department . Turk J Emerg Med. 2018, 14:47-51.10.1016/j.tjem.2018.04.004

5. Yang X, Yu Y, Xu J, et al.: Clinical course and outcomes of critically ill patients with SARS-CoV-19 pneumonia in Wuhan, China: a single-centered, retrospective, observational study. Lancet Respir Med. 2020, 10.1016/S2213-2600(20)30079-5

6. He X, Lau EHY, Wu P, et al.: Temporal dynamics in viral shedding and transmissibility of COVID-19. Nat Med. 2020, 15:10.1038/s41591-020-0869-5

7. Adly A, Youssef TA, El-Begermy MM, Younis HM: Timing of tracheostomy in patients with prolonged endotracheal intubation: a systematic review. Eur Arch Otorhinolaryngol. 2018, 275:679-690. 10.1007/s00405-017-4838-7

8. Tong CC, Kleinberger AJ, Paolino J, Altman KW: Tracheotomy timing and outcomes in the critically ill . Otolaryngol Head Neck Surg. 2012, 147:44-51. 10.1177/0194599812440262

9. van Doremalen N, Bushmaker T, Morris DH, et al.: Aerosol and surface stability of SARS-CoV-2 as compared with SARS-CoV-1. N Engl J Med. 2020, 16:1564-1567. 10.1056/NEJMc2004973 